\title{
ADOLESCENT SEXUAL HEALTH
}

\section{Attitudes about sexual disclosure and perceptions of stigma and shame}

\author{
S D Cunningham, J Tschann, J E Gurvey, J D Fortenberry, J M Ellen
}

Sex Transm Infect 2002; 78:334-338

See end of article for authors' affiliations

Correspondence to: Jonathan M Ellen, Johns

Hopkins Hospital, Park

307,600 N Wolfe Street, Baltimore, MD 21287 ,

USA; jellen@jhmi.edu

Accepted for publication 24 July 2002
Objectives: To determine the association between stigma and shame about having a sexually transmitted disease and adolescents' past STD related care seeking; between stigma, shame, and perceptions about disclosure of sexual behaviours to a doctor or nurse; and whether the association of stigma, shame, and care seeking was moderated by perceptions about disclosure.

Methods: A household sample of 142 sexually active African-American youths, 13-19 years old, was questioned about STD related stigma (alpha $=0.89$ ), STD related shame (alpha $=0.90$ ), and perceptions about disclosure of sexual behaviours to a doctor or nurse (alpha $=0.81$ ).

Results: Among females, stigma was associated with increased anticipation of negative reactions to disclosure of sexual behaviours to a doctor or nurse (odds ratio $(O R)=0.319 ; 95 \%$ confidence inter$\operatorname{val}(\mathrm{Cl})=0.12$ to 0.85 ) while shame was not. Stigma was also independently associated with STD related care seeking in the past year $(O R=0.296 ; 95 \% \mathrm{Cl}=0.09$ to 0.94 ) while shame was not. There was no association between stigma and shame with perceptions about disclosure or past care seeking in males. Perceived outcomes of disclosing sexual behaviours did not moderate the association of stigma, shame, and past STD related care seeking.

Conclusions: Stigma about STDs may influence how female adolescents perceive reactions to disclosure of their sexual behaviour to healthcare providers. It may also be an important factor in their decision seek to STD related care. Perceptions about disclosure of sexual behaviour to a doctor or nurse do not change the relation of stigma or shame to past STD related care seeking.
$\mathrm{T}$ here is an increasing realisation that non-medical, psychological factors influence decisions to obtain medical care. Delay in seeking and obtaining diagnosis and treatment for sexually transmitted diseases (STDs) can allow for continued transmission and the greater probability of adverse sequelae. Recent findings support the view that stigma and shame associated with STDs are important barriers to appropriate diagnostic and treatment services. ${ }^{1}$

Stigma is defined as an undesirable attribute in a person that is viewed as setting that person apart from the rest of society. ${ }^{2}{ }^{3}$ Shame is an intense negative emotion that results from a person experiencing failure in relation to personal or other people's standards, feeling responsible for that failure, and believing that the failure reflects an inadequate self. ${ }^{45}$ Sometimes referred to as "self stigmatisation," it is a reflection of a person's acceptance of the negative aspects of stigma. ${ }^{6}$ Although it can occur privately, shame has also been described as an affective reaction that follows public exposure of some deviation from accepted norms. ${ }^{4}$

Among adolescents, stigmatisation and feelings of shame may also be a concern regarding disclosure of sexual behaviours. Smith et al have found that, relative to other sensitive behaviours (for example, smoking, drug use), adolescents report a greater reluctance to respond honestly to questions about contracting a sexually transmitted disease, frequency of sexual intercourse, anal sex, or oral sex. ${ }^{8}$ Being reluctant to disclose such information may strongly influence whether or not adolescents would be willing to get tested or seek care for sexually related diseases.

The objective of this research was to determine, in a household sample of youths, the relation between stigma and shame about having a sexually transmitted disease and (1) past STD related care seeking and (2) perceptions about disclosure of sexual behaviours to a doctor or nurse. Of interest was whether the relation between stigma, shame, and care seeking was moderated by perceptions about disclosure. For people who have conditions that are not visibly stigmatising - that is, having an STD, avoiding situations that would involve revealing the stigma may be a way to reduce the chances of experiencing intense feelings of shame. This may take the form of being reluctant to seek health care in an effort to avoid disclosure. We hypothesised that adolescents who do not anticipate negative outcomes upon disclosure of their sexual behaviour to a doctor or nurse would be more likely to have sought STD related care, even in the face of perceived stigma or shame. Thus, perceptions about disclosure were expected to have a moderating effect on the association between perceived stigma, shame, and past STD related care seeking. STDs and their complications disproportionately affect AfricanAmerican teenagers. Therefore, our study focuses on this population.

\section{METHODS \\ Participants}

The study sample consisted of 223 African-American adolescents between the ages of 13-19 living in an economically depressed neighbourhood of San Francisco. All participants had previously participated in a telephone survey regarding sexual behaviour, STD history, and healthcare utilisation during the winter of 1996-7. ${ }^{9}$ The sample of telephone numbers used for the initial study was selected from those three prefixes that held the most promise of reaching the intervention's target population in a reasonably efficient and cost effective manner. Within the three designated prefixes, a list assisted random digit telephone sample was generated. A total of 12858 telephone numbers were sampled by the methods described above. Within 285 of the enumerated households lived one or more African-American adolescent. A total of 394 eligible adolescents resided in those households. Of the 394 eligible adolescents, 302 (77\%) agreed to be interviewed. For the current study we re-contacted eligible participants 14-18 
Table 1 Stigma, shame, and disclosure measures

\begin{tabular}{l}
\hline Scales/items \\
\hline Stigma \\
If you had an STD, people would avoid you? \\
If you had an STD, people would think you were unclean? \\
If you had an STD, other people would think badly of you? \\
If you had an STD, other people would not want to be friends with you? \\
If you had an STD other people would be disgusted by you? \\
If you had an STD, other people would be uncomfortable around you? \\
Shame \\
If you had an STD, how ashamed would you feel? \\
If you had an STD, how embarrassed would you feel? \\
If you had an STD, how guilty would you feel? \\
If you had an STD, how scared would you feel? \\
If you had an STD, how disappointed in yourself would you feel? \\
Feelings about disclosure \\
If you told a doctor or nurse that you had sexual intercourse, how likely do you think it is that \\
he or she would think less of you? \\
If you told a doctor or nurse that you had oral sex, how likely do you think it is that he or she \\
would think less of you? \\
If you told a doctor or nurse that you had anal sex, how likely do you think it is that he or she \\
would think less of you? \\
If you told a doctor or nurse that you had sex with lots of different people, how likely do you \\
think it is that he or she would think less of you?
\end{tabular}

months after their first interview and asked to them to participate in a follow up interview lasting approximately 30 minutes. Of the 299 adolescents who were contacted for the follow up, responses were not obtained for 76 of them because of the inability to locate anyone in the household, household moved out of the area, a parent refused for all adolescents in the household, or a respondent refused to participate.

The analyses performed on these data were based only on the adolescents from the sample who reported being sexually active $(n=145)$. Sexual activity was defined as having engaged in sexual intercourse with a member of the opposite sex at least once. Data on disclosure items or past STD related care seeking were missing for three subjects; these subjects were excluded from subsequent analyses.

\section{Procedure}

Data collection took place from 28 June 1998 to 15 November 1998. This study also included a mode experiment, AudioCASI instrument (developed by the Survey Research Center at University of California at Berkeley and Pulse Train, located in North Palm Beach, Florida) versus a telephone interview, to evaluate the possible differences in how respondents answer sensitive questions. ${ }^{10}$ The Audio-CASI instrument was administered on a laptop computer, with the respondent answering questions by entering responses directly utilising the mouse. The audio component to the instrument allowed the respondent to hear questions at the same time as their visual appearance on the screen. The telephone interview used the same instrument; however, an interviewer read the questions to the respondent over the telephone and entered his/her response. Forty nine per cent of the respondents used the Audio-CASI condition and $51 \%$ were interviewed by telephone. Assignment by household, rather than respondent, was done to avoid possible mode contamination within household.

This study was conducted with approval from our institutional review board. Written informed consent was obtained from participants who were 18 years or older. For participants younger than 18 years old, we obtained written informed consent from parents or guardians and written assent from the participants.

\section{Measures}

The data used in the current study consisted of items that were used to assess feelings about disclosure of sexual behav- iours and STD contraction. These data were part of a larger interview covering a number of topics relevant to the respondent's knowledge, attitudes, and behaviour regarding the healthcare system. Past STD related care seeking behaviour was assessed by participant's response when asked, "In the last 12 months, have you been checked for a sexually transmitted disease when you did not have any symptoms?"

Items developed for the current research measured STD related stigma, STD related shame, and perceptions about disclosure of sexual behaviour to a doctor or nurse (see table 1). Participants rated on four point scales the intensity of emotions (for example, embarrassment) they anticipate feeling if they had an STD ( 1 , not at all to 4 , very) and how much they agree with what other people would think of them ( 1 , strongly disagree to 4 , strongly agree). A factor analysis (principal components with varimax rotation) of responses to 11 stigma and shame items showed that the items fell into two components. STD related stigma ( six items; alpha $=0.89$ ) reflected the participant's expectation of negative interactions and judgments associated with STDs. STD related shame (five items; alpha $=0.90$ ) reflected participant's sense of shame and related negative affect states. For both scales, higher scores indicate a greater sense of stigma or shame related to STD related issues. Scale scores below the 50th percentile were reclassified to "low" and above the 50th percentile as "high." The stigma and shame scales were fairly correlated $(r=0.26)$ suggesting they are distinct but related constructs.

Participants were also asked to describe their perceptions about disclosing to a doctor or nurse whether or not they had sexual intercourse, oral sex, anal sex, and/or sex with many partners on a three point scale from "very likely to make a difference" to "wouldn't make a difference." All disclosure items were summed to yield a composite disclosure score (four items; alpha $=0.81$ ). Higher scores reflect fewer negative perceptions about disclosure of sexual behaviour to a doctor or nurse. Scores below the 50th percentile were reclassified as "Anticipate a negative reaction" and above the 50th percentile as "Anticipate that it would not make a difference."

\section{Statistical methods}

Statistical analyses were conducted using logistic regression with $95 \%$ confidence intervals for each odds ratio. Generalised estimate equations (GEE) were used to control for the 
Table 2 Sample characteristics, by sex $(n=142)$

\begin{tabular}{lll}
\hline & Male $(n=63)$ & Female $(n=79)$ \\
\hline Age, No (\%) & & \\
13 & $2(3.2)$ & $1(1.3)$ \\
14 & $6(9.5)$ & $6(7.6)$ \\
15 & $12(19.1)$ & $9(11.4)$ \\
16 & $14(22.2)$ & $10(12.7)$ \\
17 & $10(15.9)$ & $19(24.1)$ \\
18 & $12(19.1)$ & $27(34.2)$ \\
19 & $7(11.1)$ & $7(8.9)$ \\
Mode of interview, No (\%) & $34(54.0)$ & $38(48.1)$ \\
Telephone & $29(46.0)$ & $41(51.9)$ \\
A-CASl & $38(60.3)$ & $21(26.6)$ \\
STD related care, past year, No (\%) & $58(73.4)$ \\
No & $25(39.7)$ & $44(55.7)$ \\
Yes & & $35(44.3)$ \\
Stigma, No (\%) & $29(46.0)$ & $21(26.6)$ \\
Low & $34(54.0)$ & $58(73.4)$ \\
High & & $46(58.2)$ \\
Shame, No (\%) & $23(36.5)$ & $33(41.8)$ \\
Low & $40(63.5)$ & \\
High & & \\
Perceptions about disclosure of sexual behaviours, No (\%) & \\
Anticipate that it would not make a difference & $42(66.7)$ & \\
Anticipate a negative reaction & $21(33.3)$ & \\
\hline * & & \\
\hline
\end{tabular}

influence of the non-independence of participants who resided in a household where another participant lived. Interaction terms were used to assess moderation by adolescents' perceptions about disclosing sexual behaviours to a doctor or nurse. Statistical significance was accepted for $\mathrm{p}<0.05$. Results were analysed separately by sex in order to examine sex differences in perceptions of stigma, shame, and attitudes about reporting sexual behaviours to a doctor or nurse. All analyses controlled for mode of interview.

\section{RESULTS}

As shown in table 2, there were no significant differences between men and women in age, mode of interview, level of stigma, level of shame, and perceptions about disclosure of sexual behaviours to a doctor or nurse. Participants' ages ranged from 13-19 years old; $48 \%$ of participants perceived high levels of stigma associated with STDs while 69\% perceived high levels of shame. Thirty eight per cent of participants anticipated that a negative reaction would result from disclosing sexual behaviours to a doctor or nurse. Females were significantly more likely than males to have sought STD related care in the past year $(73 \%$ and $40 \%$, respectively).

Among females, stigma was significantly related to perceptions about disclosure (see table 3 ). Higher levels of perceived stigma were associated with increased odds of anticipating negative reactions as a result of disclosing sexual behaviours to a doctor or nurse (odds ratio $(\mathrm{OR})=0.319 ; 95 \%$ confidence interval $(\mathrm{CI})=0.12$ to 0.85$)$. Perceptions of shame were not associated with perceptions about disclosure to a doctor or nurse for females. Neither stigma nor shame was correlated with perceptions about disclosure to a doctor or nurse for males.

Logistic regression analysis of the effects of stigma and shame on past STD related care seeking indicates that female adolescents are less likely to have been tested for an STD if they reported high levels of stigma $(\mathrm{OR}=0.264 ; 95 \% \mathrm{CI}=$ 0.09 to 0.77 ) or shame $(\mathrm{OR}=0.196 ; 95 \% \mathrm{CI}=0.04$ to 1.8 )

Table 3 Logistic regression analysis assessing the effect of stigma and shame on perceptions about disclosure of sexual behaviours*

\begin{tabular}{|c|c|c|c|c|}
\hline \multirow[b]{2}{*}{ Independent variable $\dagger$} & \multicolumn{2}{|l|}{ Model 1 } & \multicolumn{2}{|l|}{ Model $2 \S$} \\
\hline & OR (95\% Cl) & $\mathrm{p}$ Value & OR (95\% Cl) & $\mathrm{p}$ Value \\
\hline $\begin{array}{l}\text { Males }(n=63) \text { : } \\
\text { STD related stigma }\end{array}$ & & & & \\
\hline $\begin{array}{l}\text { High } \\
\text { Low }\end{array}$ & $0.433(0.14$ to 1.3$)$ & 0.135 & $0.347(0.11$ to 1.1$)$ & 0.082 \\
\hline $\begin{array}{l}\text { STD related shame } \\
\text { High } \\
\text { Low }\end{array}$ & 1.45 (0.49 to 4.3$)$ & 0.502 & $2.00(0.60$ to 6.6$)$ & 0.259 \\
\hline $\begin{array}{l}\text { Females }(n=79) \text { : } \\
\text { STD related stigma }\end{array}$ & & & & \\
\hline $\begin{array}{l}\text { High } \\
\text { Low }\end{array}$ & $0.378(0.15$ to 0.95$)$ & 0.039 & $0.319(0.12$ to 0.85$)$ & 0.023 \\
\hline $\begin{array}{l}\text { STD related shame } \\
\text { High } \\
\text { Low }\end{array}$ & 1.35 (0.49 to 3.7$)$ & 0.561 & $1.94(0.65$ to 5.8$)$ & 0.235 \\
\hline
\end{tabular}

*Anticipate a negative reaction from disclosure $v$ anticipate that it would not make a difference if disclosed sexual behaviours. †Stigma (high=0, low=1); shame (high=0, low=1).

$\ddagger$ Adjusted for mode of interview (A-CASI $v$ telephone).

$\S$ Adjusted for mode of interview (A-CASI $v$ telephone) and other variable (stigma or shame) listed in table. 
Table 4 Logistic regression analysis assessing the effect of stigma, shame, and perceptions about disclosure on past STD care seeking behaviour*

\begin{tabular}{|c|c|c|c|c|c|c|}
\hline \multirow[b]{2}{*}{ Independent variable } & \multicolumn{2}{|l|}{ Model $1 \mp$} & \multicolumn{2}{|l|}{ Model $2 \S$} & \multicolumn{2}{|l|}{ Model 3ף } \\
\hline & OR $(95 \% \mathrm{CI})$ & $p$ Value & OR $(95 \% \mathrm{Cl})$ & p Value & OR $(95 \% \mathrm{CI})$ & p Value \\
\hline \multicolumn{7}{|l|}{ STD related stigma } \\
\hline $\begin{array}{l}\text { High } \\
\text { Low }\end{array}$ & 0.947 (0.36 to 2.5$)$ & 0.913 & $1.10(0.41$ to 3.0$)$ & 0.849 & 0.905 (0.30 to 2.7$)$ & 0.859 \\
\hline \multicolumn{7}{|l|}{ STD related shame } \\
\hline $\begin{array}{l}\text { High } \\
\text { Low }\end{array}$ & $0.665(0.25$ to 1.8$)$ & 0.416 & 0.647 (0.23 to 1.8$)$ & 0.409 & 0.696 (0.23 to 2.1$)$ & 0.526 \\
\hline \multicolumn{7}{|l|}{ Females $(n=79)$ : } \\
\hline $\begin{array}{l}\text { High } \\
\text { Low }\end{array}$ & $0.264(0.09$ to 0.77$)$ & 0.015 & $0.316(0.11$ to 0.95$)$ & 0.039 & $0.296(0.09$ to 0.94$)$ & 0.038 \\
\hline \multicolumn{7}{|l|}{ STD related shame } \\
\hline $\begin{array}{l}\text { High } \\
\text { Low }\end{array}$ & 0.196 (0.04 to 1.8$)$ & 0.039 & 0.249 (0.05 to 1.2$)$ & 0.085 & 0.260 (0.05 to 1.3$)$ & 0.097 \\
\hline $\begin{array}{l}\text { *Participants who were } n \\
\text { †Stigma (high }=0 \text {, low }=1 \text { ) } \\
\text { †Adjusted for mode of in } \\
\text { §Adjusted for mode of in } \\
\text { TAdjusted for mode of in }\end{array}$ & $\begin{array}{l}\text { ecked for an STD in the } \\
\text { ame (high=0, low }=1 \text { ). } \\
\text { ew (A-CASI } v \text { telephone) } \\
\text { ew (A-CASI } v \text { telephone) } \\
\text { ew (A-CASI } v \text { telephone) }\end{array}$ & $\begin{array}{l}12 \text { mont } \\
\text { other va } \\
\text { rceptions }\end{array}$ & $\begin{array}{l}\text { hose who were. } \\
\text { (stigma or shame) liste } \\
\text { it disclosure and other } v\end{array}$ & $\begin{array}{l}\text { table. } \\
\text { able (stign }\end{array}$ & shame) listed in table. & \\
\hline
\end{tabular}

than low (see table 4). STD related stigma continued to be a significant factor when variables for perceived level of shame and perceptions about disclosure of sexual behaviours to a doctor or nurse were added to the model (OR $=0.296$; $95 \%$ CI $=0.09$ to 0.94 ). Shame was not independently associated with past STD related care seeking once stigma was added to the model. There was not a significant difference for either stigma or shame for male adolescents.

Interaction terms were added to the model to test for potential differences in the effect of stigma and shame on past STD related care seeking as a result of perceptions about the outcome of disclosing sexual behaviours to a doctor or nurse. None of the interactions terms was significant $(p>0.1)$. Therefore, our results indicate that perceptions about the outcome of disclosing sexual behaviours to a doctor or nurse did not moderate the relation of stigma or shame and STD related care seeking in either males or females.

\section{DISCUSSION}

Among females, participants' expectation of isolation and adverse social judgment associated with STDs had a significant inverse association with perceptions about disclosure indicating that perceptions about disclosure of their sexual behaviours to a doctor or nurse would cause those people to think less of them. Thus, stigma about STDs may be an important element in these individuals decision to disclose information about their sexual behaviours to health practitioners. This relation of stigma to disclosure is consistent with Goffman's perspective on information control among those with less visible marks. ${ }^{2}$ Part of STD related care seeking involves speaking with a doctor or nurse about sexual behaviour and potential STDs. Stigma as a barrier to communication with clinicians could potentially pose an important barrier to care.

High levels of STD related stigma were also associated with decreased likelihood for females to have sought STD related care during the past year. Stigma, therefore, may be an important element of adolescents' decision to seek STD related health care. One way to escape the uncomfortable feelings elicited by stigma and shame is to hide or withdraw from further social contact. ${ }^{2112}$ Avoiding the social interaction required for STD related care may be a way in which some adolescents prevent feeling stigmatised.

In this study, STD related shame was not associated with the decision to seek STD related care. That is not to say that negative emotions are not part of the STD experience. Stigma and shame are distinct but related constructs. For instance, if shame is one of the emotional consequences of stigmatisation, then it is likely to partially underlie the psychopathology that so often occurs with stigmatisation. ${ }^{3}$ In addition to stigma, qualitative work has described several negative emotions that are part of some people's experience attending sexual health clinics and their subsequent diagnoses of an STD. ${ }^{13} 14$

Our findings of a relation between stigma and care seeking are consistent with recent findings that "shame is part of the experience of seeking STD related care but stigma may be a more powerful barrier to STD related care."1 However, an important difference between these two studies is the methodology used to recruit subjects. In our study, household sampling was done to include adolescents who might not seek healthcare services. Past studies on the topic of stigma and shame have been biased by their exclusive use of clinic populations. In general, there is an emerging consistency of findings of stigma and shame as a barrier to various aspects of STD related care.

This is the first study to examine the role of adolescents' attitudes about disclosure of sexual behaviours to a doctor or nurse in the association between stigma, shame, and seeking STD related care. Although stigmatisation and disclosure are closely tied, our results show that perceptions about the outcome of disclosing sexual behaviours to a doctor or nurse did not moderate the effect of stigma and shame on past STD related care seeking. Perceptions about disclosure of sexual behaviours to a doctor or nurse did not change the relation of stigma or shame on whether adolescents sought STD related care. This finding bolsters our conclusion that stigma may be an important barrier to STD related health care.

If it is true that sexual behaviour of women is subject to greater social controls, and if women are seen to have more responsibility for sexual activity and its consequences, social attribution theory suggests that women would perceive more stigma associated with STDs. There is also evidence that females may be more likely than males to develop a shame prone affective style. ${ }^{15}{ }^{16}$ These sex differences in the tendency to experience shame may partially explain why female adolescents who have symptoms of an STD have been found to take more time to obtain care than asymptomatic female adolescents or symptomatic male adolescents. ${ }^{17}$ Likewise, our results demonstrate that perceptions of stigma may hinder female adolescents from obtaining STD screening. 


\section{Key messages}

- Stigma about STDs may influence a female adolescent's decision to disclose information about her sexual behaviour to health practitioners

- Perceptions about stigma associated with STDs may also be an important element of a female adolescent's decision to seek STD related care

- Perceptions about the outcome of disclosure of sexual behaviours to a doctor or nurse do not moderate the relation of stigma or shame on past STD related care seeking

There were several limitations to this study. Firstly, owing to the cross sectional nature of this research, we cannot make causal interpretations. Secondly, the small sample size may account for the lack of a relation between shame and past STD related care seeking. A third limitation is the generalisability of our findings. Participants were urban African-American adolescents living in a neighbourhood with high rates of STDs. Perceptions about stigma and shame associated with STDs may vary in other parts of the country.

An understanding of the factors related to health seeking behaviour is important if STD control programmes are to be effective. Identifying some of the ways in which adolescents may feel stigmatised by reporting their sexual behaviours is important in order to fully understand how this may serve as a barrier to seeking care for STDs. In addition, our findings suggest that interventions need to target and future studies should explore ways in which people arrive at a high level of stigma as a result of seeking STD related care, particularly ways that might be modifiable.

\section{ACKNOWLEDGEMENTS}

This work was supported, in part, by grants from the National Center for STD, HIV and TB, Division of HIV Prevention, Centers for Disease Control and Prevention (grant U62-CCU914805-01), National Institute of Allergy and Infectious Diseases (grant 2R01-AI36986), and Maternal and Child Health Bureau, Health Resources and Services Administration (grant MCJ000978). We would like to dedicate this manuscript to the memory of Karen Garrett whose commitment to the implementation of the project ensured its success.

\section{CONTRIBUTORS}

Each of the authors made valuable contributions to the manuscript. SDC was responsible for the analysis and writing; DF contributed to the design and analysis of the research; JEG, JT, and JME developed and implemented the project and contributed to the analysis and writing.

\section{Authors' affiliations}

S D Cunningham, J E Gurvey, J M Ellen, Division of General Pediatrics and Adolescent Medicine, Department of Pediatrics, Johns Hopkins School of Medicine, USA

J Tschann, Department of Psychiatry, School of Medicine, University of California, San Francisco, USA

J D Fortenberry, Section of Adolescent Medicine, Indiana University School of Medicine, Indianapolis

\section{REFERENCES}

1 Fortenberry JD, McFarlane M, Bleakley A, et al. Relationships of stigma and shame to gonorrhea and human immunodeficiency virus screening. Am J Public Health 2002;92:378-81.

2 Goffman E. Stigma: notes on the management of spoiled identity. Englewood Cliffs NJ: Prentice Hall, 1963

3 Lewis M. Shame and stigma. In: Gilbert P, Andrews B, eds. Shame: interpersonal behavior, psychopathology, and culture. New York: Oxford University Press, 1999: 126-40.

4 Lewis M. Embarrassment: the emotion of self exposure and embarrassment. In: Tangney JP, Fischer, eds. Self-conscious emotions: the psychology of shame, guilt, embarrassment and pride. New York: Guilford Press, 1995: 198-218

5 Tangney JP. Assessing individual differences in proneness to shame and guilt: Development of the Self-Conscious Affect and Attribution Inventory. J Personality Social Psychology 1990;59:102-11.

6 Corrigan PW, Penn DL. Lessons from social psychology on discrediting psychiatric stigma. Am Psychol 1999:126-40.

7 Tangney JP, Rowland MS, Flicker L, et al. Are shame, guilt, and embarrassment distinct emotions? J Personality Social Psychology 1996:70:1256-69.

8 Smith LB, Adler NE, Tschann JM. Underreporting sensitive behaviors: the case of young women's willingness to report abortion. Health Psychology 1999: 18:37-43.

9 Ellen JM, Lane MA, Garrett K, et al. Are adolescents being screened for sexually transmitted diseases? Sex Transm Infect 2000;76:94-7.

10 Ellen JM, Gurvey JE, Pasch L, et al. Differences in rates of self-reported HIV risk behaviors by mode of data collection. J Adolescent Health 2002; (in press).

11 Fischer KW, Tangney JP. Self-conscious emotions and the affect revolution: Framework and overview. In: Tangney JP, Fischer, eds. Self-conscious emotions: the psychology of shame, guilt, embarrassment and pride. New York: Guilford Press, 1995:3-22.

12 Barrett KC. A functionalist approach to shame and guilt. In Tangney JP, Fischer, eds. Self-conscious emotions: the psychology of shame, guilt, embarrassment and pride. New York: Guilford Press, 1995:25-63.

13 Holgate HS, Longman C. Some peoples' psychological experiences of attending a sexual health clinic and having a sexually transmitted infection. J Roy Soc Health 1998; 1 18:94-6.

14 Duncan B, Graham H, Scoular A, et al. Qualitative analysis of psychosocial impact of diagnosis of Chlamydia trachomatis: implications for screening. BM 2001;322:195-9.

15 Lewis HB. Psychic war in men and women. New York: New York University Press 1976.

16 Wright F, O'Leary JO, Balkin J. Shame, guilt, narcissism, and depression: correlates and sex differences. Psychoanalytic Psychology 1987;7:285-9.

17 Fortenberry JD. Health care seeking behaviors related to sexually transmitted diseases among adolescents. Am J Public Health 1997;87:417-20. 